\title{
ANÁLISE DOS DIZERES DE ROTULAGEM DE PRODUTOS COSMÉTICOS FOTOPROTETORES, SOB AS EXIGÊNCIAS LEGAIS VIGENTES
}

\section{ANALYSIS OF PHOTOPROTECTION COSMETIC PRODUCTS LABELS INFORMATION UNDER THE EFFECTIVE LEGAL DEMANDS}

\author{
OLIVEIRA, Andrezza Beatriz'; OYAKAWA, Carlos Norio'; MIGUEL, Marilis Dallarmi2; ZANIN, \\ Sandra M. W. ${ }^{3}$; CHOCIAl, Jorge Guido ${ }^{4}$
}

\author{
1.Acadêmicos do curso de Farmácia - UFPR; \\ 2.Mestre em Educação PUC-PR, Doutora em Prod. Vegetal - UFPR, Disciplina de Farmacotécnica, email: dallarmi@onda.com.br \\ 3. Mestre em Bioquímica -UFPR, Disciplina de Farmacotécnica \\ 4. Mestre em Ciências, Bioquímica-UFPR, Disciplina de Tecnologia de Cosméticos
}

RESUMO

O uso de fotoprotetores é exaltado durante a estação sazonal verão, quando a busca pela pigmentação cutânea através da exposição ao sol torna-se maior. A proteção da pele contra a irradiação solar se faz importante sobretudo para evitar a incidência de efeitos eritematógenos, queimaduras solares, carcinomas e melanomas cutâneos, e fotoenvelhecimento. No entanto, a orientação profissional quanto ao uso correto deste produto é praticamente inexistente, cabendo ao usuário a responsabilidade sobre a escolha, aquisição e uso. Assim, evidencia-se a importância da presença de informações relativas aos produtos e seu uso, nos dizeres de rotulagem de cada produto, em cumprimento às exigências da legislação sanitária. Para verificar o cumprimento da regulamentação em questão, fez-se um levantamento das informações contidas em rótulos de produtos fotoprotetores, tendo como foco principal, aquelas consideradas obrigatórias pela legislação. Após análise percentual, verificou-se que os dizeres de rotulagem, em alguns produtos, apresentam falhas no que diz respeito às informações importantes para a garantia da escolha e do seu uso correto e seguro. Neste contexto destaca-se a orientação do farmacêutico durante o atendimento ao público, dentro da prática da Atenção Farmacêutica.

Palavras-chave: Fotoprotetores, Rotulagem, Orientação Farmacêutica.

ABSTRACT

The photoprotectors use are exalted during Summer, when searching skin pigmentation by sun exposure is increased. Skin protection for sun radiation is important especially to avoid eritematogenous efects, sun burning, skin carcinoma and melanoma, and photoaging incidence. However professional guidance about right using of these products is decreased, bringing responsability about correct using and acquisition to consumer. This increases using and recommendation information presence at photoprotector labels importance, obeying to Colleged Directory Resolution 237/2002 Sanitary Vigilance National Agency. This rule's fulfilment was verified by photoprotection products labels information checking, on a way of consider obligatory items. Statistics analysis shows up fails in giving important information for correct production. This context emphasize pharmaceutical guidance in Pharmaceutical Care. Pharmacist is health professional who has on training interface with users. In this way, contributes in community health keeping and life conditions improvement. Key words: Rule, Labeling, Pharmaceutical Care, Photoprotectors.

INTRODUÇÃO

A estação sazonal verão tem sido caracterizada pela maior exposição das pessoas ao sol à beira da orla marítima, buscando a pigmentação dourada da pele (bronzeamento), que ocorre como reação natural do organismo contra a agressão solar, por meio da migração de grânulos de melanina incolores formados nas células basais, em conseqüência da exposição aos raios UVB, ao extrato córneo, onde são oxidados pela radiação UVA, transformando-se em melanina corada (FElJÓ, 2001). A defesa orgânica se dá contra a formação de radicais livres pela radiação UVA, que posteriormente oxidam o DNA celular, e contra a ação direta da radiação UVB sobre o DNA (MILANI, 2002). A melanina apresenta proteção significativa contra a radiação UVA e parcial contra UVB (SANTORO, 2001).

Sob o aspecto geográfico, a zona climática tropical encontra-se entre as latitudes $27^{\circ} 27^{\prime} 30^{\prime \prime}$ norte e sul da linha do Equador. Sua característica é a predominância de 
temperaturas elevadas, com ausência de estação propriamente fria (COELHO, 1994). Isto deve-se à incidência perpendicular dos raios solares sobre a superfície, que permite o alcance de maior número de fótons de energia, justificado pela ausência de desvios causados por difração dos raios na atmosfera ocorrentes em áreas de maior latitude. O Brasil está localizado

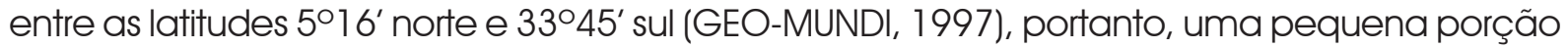
territorial encontra-se na zona subtropical, com verões moderadamente quentes e invernos amenizados pela ação de correntes marítimas quentes (COELHO, 1994). Entretanto, os raios solares sofrem pouca difusão para atingir a superfície. Os brasileiros expõem-se diariamente a radiação solar que incide diretamente, portanto faz-se necessária a proteção cutânea com produtos contendo substâncias fotoprotetoras.

A composição energética do espectro solar proporciona aproximadamente $5 \%$ de radiação ultra-violeta (UV), 45\% de radiação visível e 50\% de radiação infra-vermelha (IV, IR). Os raios IV são sobretudo calóricos, possuem ação química débil e por serem pouco energéticos são levemente nocivos para a pele. A luz visível possui grau diverso de energia calórica, luminosa e química, enquanto a radiação UV representa o componente com maior poder energético do espectro solar, subdividida em raios UVA (não eritematógenos, porém possuem poder pigmentógeno), UVB (eritematógenos responsáveis pelas queimaduras solares e da pigmentação indireta, além da conversão do colesterol cutâneo em vitamina D), UVC (bloqueados pela camada de ozônio, são pouco eritematógenos, pouco pigmentógenos e muito bactericidas) (VIGLIOLA, 1991). Os efeitos fisiológicos da radiação solar incluem a síntese de vitamina D, ativação da circulação, aumento da formação de anticorpos, de eritrócitos e de hemoglobina, eritema calórico e queimadura solar, indução de carcinomas e melanomas cutâneos, acne, fotoenvelhecimento, pigmentação cutânea, além do efeito psicológico. Pode induzir a reações fotossensíveis a drogas, dermato-helioses, catarata ocular (SOUZA, 2000; FEIJÓ, 2001; STEINER, 2001).

Os fotoprotetores são classificados em protetores (protetores e bloqueadores) e bronzeadores (bronzeadores, moderadores, ativadores de bronzeado e simuladores de bronzeado) (FEIJÓ, 2001). Estes produtos em geral contém filtros solares, cujo mecanismo de ação inclui absorção, difusão e reflexão dos raios solares (SOUZA, 2000). Para fornecer ampla proteção com maior eficácia contra a radiação solar, filtros físicos são combinados com filtros químicos (SANTORO, 2001). Em geral, estes produtos são apresentados sob a forma de emulsões A/O ou O/A, géis, pomadas, loções hidroalcoólicas, pastas, lápis / bastões labiais, aerosóis. A maioria destes produtos tem ação anti-UVB, porém a associação com anti-UVA é pertinente (SOUZA, 2000; PAOLA, 2001). A capacidade de fotoproteção de um filtro é associada ao FPS (Fator de Proteção Solar), definido como sendo a razão entre a dose mínima eritematosa na pele protegida e a dose mínima eritematosa na pele não protegida (MINISTÉRIO DA SAÚDE, 2002).

Atualmente muito se tem discutido sobre malefícios da exposição prolongada ao sol, sob os pontos de vista médico e cosmético, com destaque para o fotoenvelhecimento e o câncer de pele (PAOLA, 2001).

Os fotoprotetores são produtos de livre comercialização, colocados à disposição ao usuário, o qual tem se responsabilizado pela escolha, raramente contando com a orientação profissional. Portanto, para garantir o uso correto e para o alcance dos benefícios esperados, é máxima a importância da clareza das informações constantes nos rótulos dos produtos, conforme a legislação vigente. 


\section{METODOLOGIA}

Para verificação do cumprimento das exigências da legislação vigente, buscou-se identificar nos rótulos de produtos de diferentes marcas a presença dos itens mínimos exigidos.

Realizou-se então um levantamento dos dados constantes nos rótulos de 24 marcas de produtos fotoprotetores disponíveis para a comercialização em farmácias e supermercados no município de Curitiba. Utilizou-se como instrumento ficha de rotulagem para protetores, bronzeadores, bloqueadores e moderadores solares, constituída por rol de itens obrigatórios e de rotulagem específica para estes produtos preconizada pela RDC 273/ 02 da ANVISA. A leitura cuidadosa dos rótulos de embalagens primária e secundária dos produtos foi imprescindível para a avaliação do cumprimento normativo. Os resultados obtidos foram submetidos a análise percentual.

\section{RESULTADOS E DISCUSSÃO}

Os resultados obtidos pela análise de produtos de 24 marcas diferentes encontram-se representados nas tabelas 1 e 2 e gráficos 1, 2, 3 e 4 .

TABELA 1 - RESULTADOS DA ANÁLISE DE RÓTULOS DE FOTOPROTETORES

\begin{tabular}{cc}
\hline Item obrigatório & $\begin{array}{c}\text { Porcentagem de cumprimento } \\
\text { normativo }\end{array}$ \\
\hline Nome do produto & 100 \\
Marca & 100 \\
No registro/resolução & 91,67 \\
Lote ou partida & 91,67 \\
Prazo de validade & 95,83 \\
Conteúdo & 95,83 \\
País de origem & 91,67 \\
Fabricante / importador & 95,83 \\
Domicílio fabricante / importador & 91,67 \\
Modo de uso (se for o caso) & 95,83 \\
Advertências / Restrições (se for o caso) & 95,83 \\
Composição & 95,83 \\
CNPJ & 91,67 \\
Finalidade do produto, quando não implicita no nome & 87,5 \\
Fo FPS & 95,83 \\
Fototipo de pele & 58,33 \\
Nível de proteção & 58,33 \\
Comportamento da pele à irradiação solar & 58,33 \\
Indicar necessidade de reaplicação & 95,83 \\
Explicação sobre o número de FPS & 58,33 \\
\hline
\end{tabular}

TABELA 2 - RESULTADOS DA ANÁLISE DE RÓTULOS DE FOTOPROTETORES VOLTADOS AO USO INFANTIL

Advertência

"Este produto não oferece nenhuma proteção contra insolação"

"Quando aplicado em crianças, deve-se evitar demasiada exposição ao sol"

"Para uso em crianças menores que 6 meses, consulte o médico"
Porcentagem de cumprimento normativo

37,5

29,17

25 


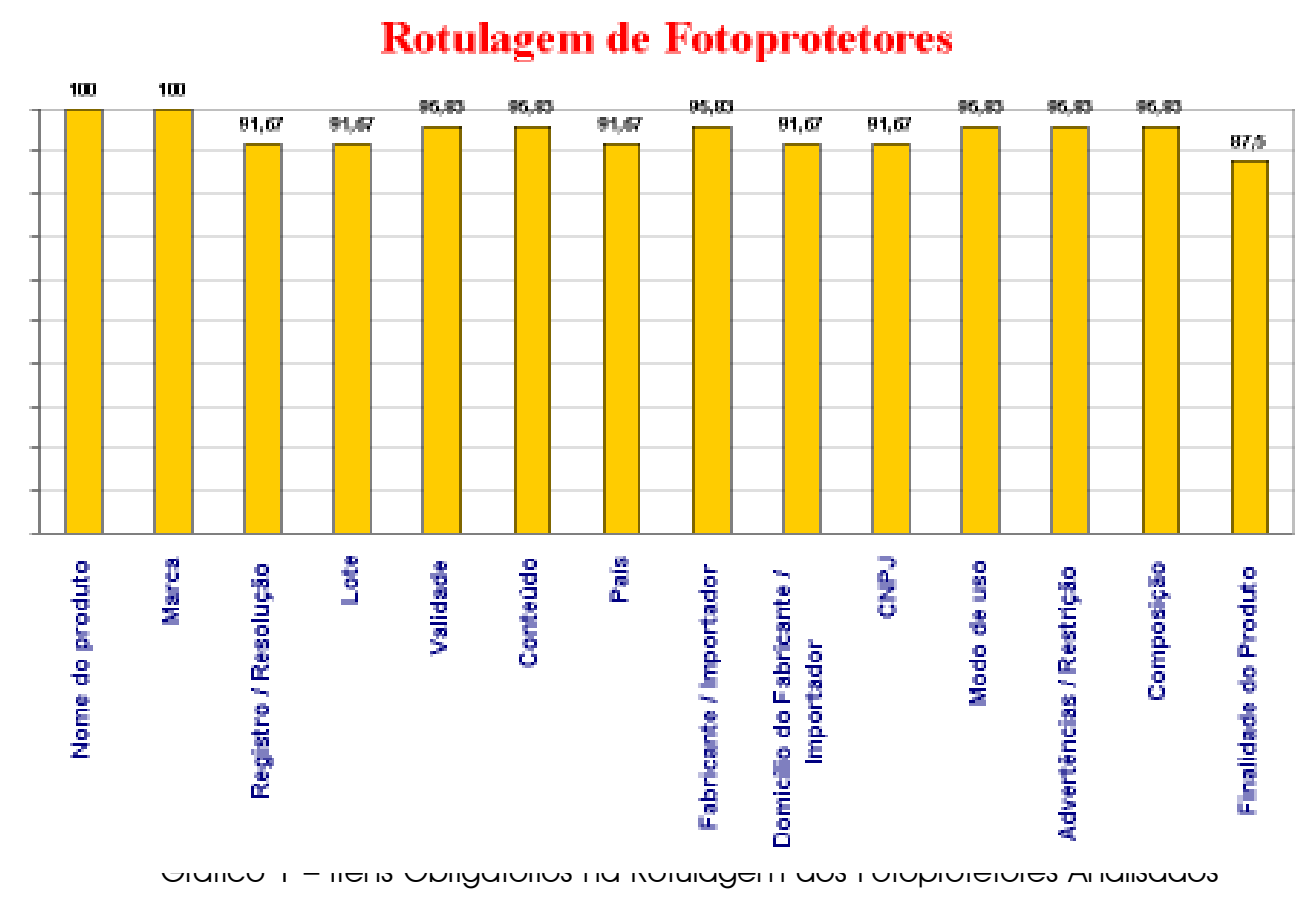

Os resultados observados demonstram que nem todas as embalagens analisadas apresentam os itens considerados obrigatórios pela legislação. Apenas os itens "Nome do Produto" e "Marca" foram visualizadas em todos os produtos, caracterizando a falta de algumas informações essenciais ao usuário no que diz respeito à efetividade e segurança do produto.

Os itens de freqüências subsequentes são aqueles de maior interesse ao consumidor ("Prazo de validade", "Conteúdo", "Modo de uso", "Advertências", "Composição", com 95,83\% de ocorrência). Os menos freqüentes são dados que se referem à produção e à empresa ("Lote", "Número de registro do produto", "CNPJ"), incluindo rastreabilidade ("País de origem", "Domicílio"), com 91,67\% de ocorrência. O item "Finalidade do Produto" apresentou ocorrência de $87,5 \%$.

Rotulagem específica para Fotoprotetores

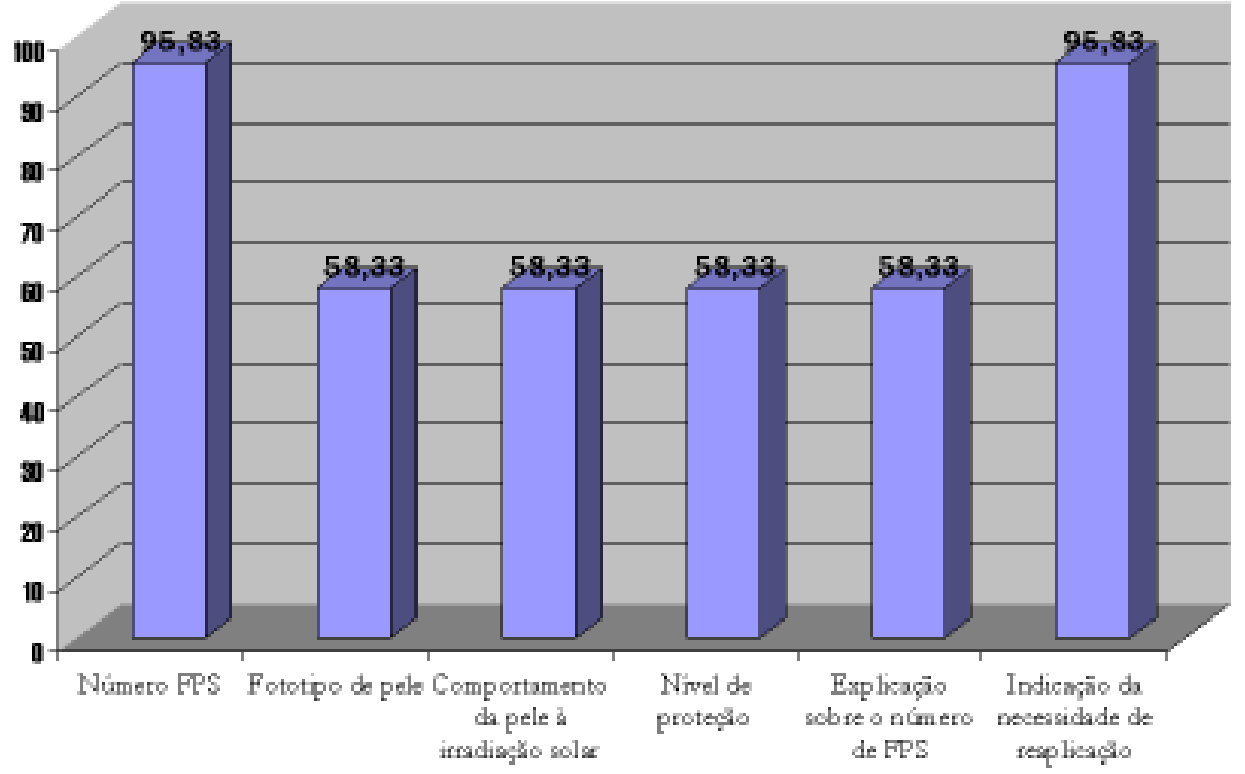

Gráfico 2 - Freqüência de Itens de Rotulagem Específica para Fotoprotetores Verificada nos Produtos Analisados 
Quanto aos itens específicos para fotoprotetores, que segundo a RDC 237/02 devem constar na embalagem, apenas o número de FPS e a indicação da necessidade de reaplicação foram observados com maior freqüência, ainda assim, não na totalidade dos produtos analisados (ocorrência de 95,83\%). Estes representam os itens de rotulagem mais observados pelo consumidor no momento da escolha. Constatou-se que outros itens de rotulagem específica não ocorrem com a mesma freqüência ("Fototipo de pele", "Comportamento da pele frente à irradiação solar", "Nível de proteção", "Explicação sobre o número de FPS"), demonstrando falhas no que diz respeito à presença de informações imprescindíveis ao consumidor e que podem comprometer o uso correto e seguro do produto.

Tal temática torna-se ainda mais importante quando os produtos de uso infantil são abordados. Conforme verificado no gráfico 3,21\% dos produtos analisados são voltados ao uso infantil, e estes devem apresentar indicativos de precauções a serem tomadas, no rótulo. Entretanto, como mostra o gráfico 4 e a tabela 2, nem todos os produtos para uso infantil apresentam tais advertências. As ocorrências verificadas foram 37,5\% para "Este produto não oferece nenhuma proteção contra insolação", 29,17\% para "Quando aplicado em crianças, deve-se evitar demasiada exposição ao sol", 25\% para "Consultar o médico para uso em crianças menores de seis meses", e 8,33\% dos produtos voltados ao uso infantil não apresentaram nenhuma advertência neste sentido.

\section{Fotoprotetores especificos para uso infantil}

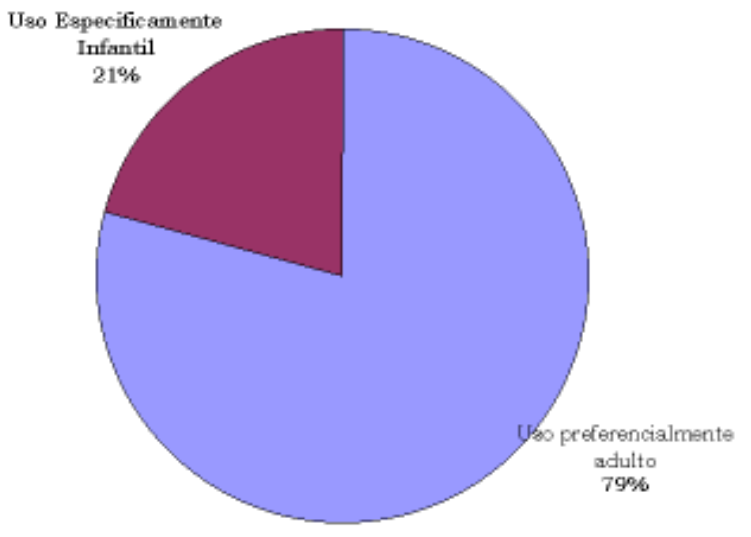

Gráfico 3 - Produtos voltados ao uso infantil

Adorertências sarn o Lso lafantil

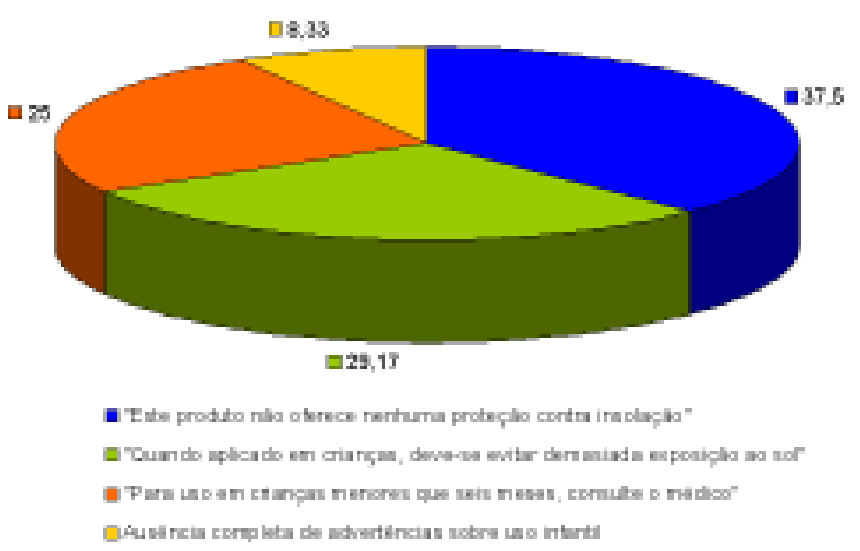

Gráfico 4 - Advertências contidas nos rótulos de fotoprotetores para uso infantil 
A ausência ou falha na orientação sobre a utilização de fotoprotetores, que deve estar presente nos dizeres de rotulagem destes produtos, pode levar ao uso incorreto e a danos ao usuário, agravando-se o quadro, quando se faz referência a produtos para uso infantil, pois a pele de crianças apresenta maior sensibilidade à exposição solar.

\section{CONSIDERAÇÕES}

A fotoproteção assume papel importante na manutenção da saúde e beleza da pele (PAOLA, 2001). O uso correto dos produtos fotoprotetores, o entendimento do significado de parâmetros como FPS, forma cosmética (forma de apresentação), e outros, podem ser garantidos apenas pela disseminação de informações constantes dos dizeres de rotulagem dos produtos, ou pela orientação profissional. As classes médica e farmacêutica têm procurado aumentar o nível de consciência do público no que se refere aos efeitos adversos da exposição excessiva à radiação solar, bem como do papel profilático que dos fotoprotetores (NAKAZAWA, 2001).

A consulta clínica dermatológica é praticada com pouca freqüência, por dificuldades inerentes à condições sócio-econômicas da população, escassez de especialistas atendentes nos serviços de atendimento à saúde pública, ou pela idealização cultural popular de que problemas cutâneos apresentam pouca gravidade, entre outros. Dentro deste contexto, o farmacêutico como profissional da saúde, com profundo conhecimento sobre esta temática, com ałuação direta na interface com o usuário, deve ter participação efetiva para o avanço na questão da fotoproteção (OLIVEIRA, 2001).

Também neste contexto, insere-se o conceito de Atenção Farmacêutica, "um serviço a ser prestado pelo farmacêutico diretamente ao paciente, que consiste na somatória de atitudes, comportamentos, responsabilidades e habilidades do profissional na utilização da farmacoterapia, aplicando seu conhecimento em prol do alcance de resultados terapêuticos definidos na saúde e qualidade de vida do usuário" (OMS, 1993). Nesta atuação, o farmacêutico tem como principais instrumentos o conhecimento técnico-científico e a comunicação explicativa, representando uma ligação entre o paciente/usuário e o clínico, por meio de produtos cuja ação objetiva a garantia da saúde (OLIVEIRA, OLIVEIRA, 2002; BISSON, 2003).

\section{CONCLUSÃO}

A exposição ao sol deve ser controlada de modo a manter equilibrados seus efeitos benéficos (aquecimento, produção de vitamina $D$, ação antidepressiva) e malefícios (queimaduras, fotoenvelhecimento, câncer). Para tanto, faz-se uso de fotoprotetores, que possuem filtros solares físicos e/ou químicos em sua constituição.

A ausência de informações pertinentes ao uso correto de fotoprotetores pode acarretar na ineficácia do produto, e consequentemente em todos os efeitos nocivos da exposição excessiva ao sol. Os problemas podem ser agravados quando se trata de produtos para o uso infantil, penalizando-se as crianças pela negligência dos responsáveis pelo produto e pela falta de informação de seus pais ou responsáveis (OLIVEIRA, 2002).

O uso correto pode ser garantido por orientação profissional do farmacêutico, profissional da saúde que apresenta maior proximidade com o usuário e cuja formação contempla o conhecimento em fotoproteção e das formas de apresentação dos produtos. 
A aplicação prática dos conhecimentos técnicos/científicos sobre esta temática, na farmácia de dispensação deve acontecer na prática da Atenção Farmacêutica, durante o atendimento e orientação ao usuário. A efetividade deste serviço resgata não apenas o acompanhamento e manutenção da saúde da população, mas também a forma de prestar informações e orientações, colaborando sobremaneira para a melhoria das condições de vida da comunidade.

\section{REFERÊNCIAS}

ANVISA. Diário Oficial [da] República Federativa do Brasil. Brasilia : Resolução RDC 237 de 22 de agosto de 2002.

BISSON, M. P. Farmácia Clínica e Atenção Farmacêutica. São Paulo : Medfarma Livraria e Editora, 2003.

COELHO, M. A. Geografia Geral - O espaço natural e sócio-econômico. 3 ed. Editora Moderna Ltda : São Paulo; 1994. p. 65-91.

FEIJÓ, C. S. Fotoprotetores. 2001. Disponível em <<hnttp://www.panvel.com.br/dicas/protetores.htm $>>$

GEO-MUNDI. Brasil: Território, Localização e Limites. 1997. Disponível em: <http://www.geocities.com/geo_mundi/ brl.htm>

MILANI, F. I. Proteção Solar. Cosmetologia: Pesquisa, Desenvolvimento e Produção. Curitiba, 2002.

NAKAZAWA, T. A. Filtros Solares. 8 p. Curitiba, 2001.

OLIVEIRA, A. B.; MIGUEL, M. D.; ZANIN, S. M. Uma Análise da Atenção Farmacêutica. São Paulo : Infarma, v. 13, n. 9/10, 2001.

OLIVEIRA, A. B.; SOUZA, M. T.; MIGUEL, M. D.; ZANIN, S. M.; CHOCIAl, J. G.; MIGUEL, O. G. A Atenção Farmacêutica em Relação aos Instrumentos de Medida Volumétrica de Medicamentos. São Paulo : Infarma, v. 14, n. 5/6, 2002.

OLIVEIRA, A. B.; OLIVEIRA, A. O.; MIGUEL, M. D.; ZANIN, S. M.; KERBER, V. A. O Hipotireoidismo sob a Ótica Farmacêutica Generalista. Curitiba : Visão Acadêmica, v. 3, n. 2, 2002. p. 109-118.

OMS-OPS. El Papel del Famacéutico en el Sistema de Atención de Salud. (OPS/HSS/HSE/95.01). Tokio, Japón : Informe de la reunión de la OMS; 1993.

PAOLA, M. V. R. V. Princípios de Formulação de Protetores Solares. Cosmetics \& Toiletries, V. 13, set/out 2001. p. 7482.

SANTORO, M. I. R. M.; SILVA, F. C.; KEDOR-HACKMANN, E. R. M. Preparação e Análise de Emulsões com Filtros UV e IV. Cosmetics \& Toiletries, V. 13, set/out 2001. p. 46-54.

SOUZA, F. R. Filtros Solares. 2000. Disponível em: <http://netpage.em.com/theriaga/>

STEINER, D.; BEDIN, V. Filtros solares: O que há de Novo? Cosmetics \& Toiletries, V. 13, set/out 2001. p. 20

VIGLIOLA, P. A.; RUBIN, J. Cosmiatria II. 2 ed. Americana Publicaciones S. A. : Buenos Aires; 1991. p. 120-135. 